\title{
Association between polymorphisms in glutathione $S$-transferase Mu3 and IgG titer levels in serum against Helicobacter pylori
}

\author{
Masayuki Tatemichi ${ }^{1,2}$, Motoki Iwasaki ${ }^{2}$, Shizuka Sasazuki ${ }^{2}$ and Shoichiro Tsugane ${ }^{2}$
}

This study investigated the association between glutathione $S$-transferases (GST) polymorphisms and immunoglobin G (IgG) titer levels in serum against Helicobacter pylori (H. pylori). Out of a total $\mathbf{3 0 0}$ healthy subjects seropositive for $\boldsymbol{H}$. pylori, we analyzed the relationship between 15 single-nucleotide polymorphisms (SNPs), namely two in GST-mu2 (GST-M2), five in GST-mu3 (GST-M3), four in GST-pi1 (GST-P1) and four in GST-theta2 (GST-T2), and IgG antibody titer levels in serum against cytotoxin-associated gene $A$ (CagA) and the surface antigen of $\boldsymbol{H}$. pylori (Hp), as well as the levels of pepsinogen I (PGI). Titer levels were classified by tertile. The age-sex adjusted odds ratios (ORs) and $95 \%$ confidence intervals (Cls) in the middle and low titer groups were calculated using a polytomous logistic regression model, with the high titer group considered as control. Results for GST-M3 showed a significant association between SNPs, CagA and Hp titers. In addition, the AA genotype (high enzyme activity) from SNP rs7483 (Val224lle) in GST-M3 showed a significantly low risk for being in the low titer group (OR: $0.48,95 \% \mathrm{Cl}: 0.27-0.86$ and OR: $0.46,95 \% \mathrm{Cl}: 0.26-0.83$ for CagA and $\mathrm{Hp}$, respectively). Furthermore, the AA genotype from the rs7483 SNP showed significantly $(P<0.05)$ higher PGI levels than did the genotypes harboring a $G$ allele (mean (s.d.) $=66.9$ (32.0) and 59.1 (30.7) $\mu \mathrm{g} \mathrm{ml}^{-1}$ for $A A$ and $A G+G G$, respectively). Our results suggest that GST-M3 polymorphisms are associated with levels of IgG titer in serum against $\boldsymbol{H}$. pylori. GST-M3 activity is possibly involved in protection against mucosal atrophy caused by $\mathbf{H}$. pylori as the levels of IgG titer and PGI are linked to mucosal status. Journal of Human Genetics (2009) 54, 557-563; doi:10.1038/jhg.2009.77; published online 21 August 2009

Keywords: GST-Mu3; Helicobacter pylori; IgG titer; polymorphism

\section{INTRODUCTION}

Helicobacter pylori (H. pylori) causes chronic inflammation of the gastric mucosa, resulting in mucosal pathogenesis and atrophy. ${ }^{1,2}$ H. pylori causes the release of a number of oxidant radicals produced by inflammatory cells, leading to mucosal damage. ${ }^{3}$ The antioxidant activity of cellular enzymes therefore has an important role in the prevention of mucosal damage progression.

Human glutathione $S$-transferases (GSTs) compose a superfamily of enzymes involved in phase II of detoxification. ${ }^{4}$ GSTs protect cells against toxic chemical insults by detoxifying a variety of active metabolites. ${ }^{4}$ Further, earlier studies have shown an association between GST polymorphisms and risk of gastric cancer. ${ }^{5}$ In addition to detoxification, GSTs have a crucial role in cellular protection against oxidative stress by eliminating free radicals. ${ }^{6}$ Variations in expression and activity of these enzymes in individuals owing to genomic polymorphisms in GSTs may therefore affect the outcome of $H$. pylori infection, namely mucosal atrophy.

Helicobacter pylori serological test is performed to detect $H$. pylori infection and to determine the status of the gastric mucosa. ${ }^{7,8}$ It was shown earlier that the eradication of $H$. pylori significantly and promptly reduced the level of immunoglobin G (IgG) titer against the surface antigen of $\mathrm{H}$. pylori (Hp). ${ }^{9}$ These findings suggest the use of this IgG titer as a marker of $H$. pylori density, with high and low H. pylori densities associated with inflammation and mucosal atrophy, respectively. In addition to $\mathrm{Hp}$, an IgG titer against cytotoxinassociated gene $\mathrm{A}(\mathrm{CagA})$ is a useful marker used to detect high-risk populations for gastric cancer. ${ }^{10-12}$ The majority of $H$. pylori infections in the Japanese population are CagA-positive, and low titer levels against CagA and surface antigen of H. pylori are linked to progression of mucosal atrophy and risk of gastric cancer. ${ }^{12}$

These observations and our earlier finding ${ }^{13}$ indicate that $\operatorname{IgG}$ antibody titers are biomarkers that may prove useful in the management of $H$. pylori infection and prevention of gastric cancer. Regarding the association with gastric atrophy by infection of $H$. pylori, a lot of gene polymorphisms have been reported. They include proinflammatory cytokines, immunoresponse related and mediator genes: interleukin (IL)-1B, IL-2, IL-4, IL-13, PTPN11, RANTES and

${ }^{1}$ Department of Hygiene and Preventive Medicine, School of Medicine, Showa University, Shinagawa-ku, Tokyo, Japan and 2Epidemiology and Prevention Division, Research Center for Cancer Prevention and Screening, National Cancer Center, Chuo-ku, Tokyo, Japan

Correspondence: Dr M Tatemichi, Department of Hygiene and Preventive Medicine, School of Medicine, Showa University, 1-5-8 Hatanodai, Shinagawa-ku, Tokyo 142-8555, Japan.

E-mail: tatemichi@med.showa-u.ac.jp

Received 2 May 2009; revised 24 June 2009; accepted 24 July 2009; published online 21 August 2009 
tumor necrosis factor- $\alpha$ (reviewed by Hamajima et al. ${ }^{14}$ ). To date, however, no studies have investigated the association between polymorphisms in GSTs and the serology of $H$. pylori. Here, we have first reported a possible association between polymorphisms in GST-mu3 (GST-M3) and levels of IgG antibody titer against $H$. pylori.

\section{MATERIALS AND METHODS}

Study population and design are described in detail in an earlier study. ${ }^{15}$ Data from control subjects in a hospital-based case-control study were used. Briefly, subjects were selected among patients having visited two hospitals for medical check-ups, including for endoscopy and X-ray of the upper gastrointestinal tract, fecal occult blood testing and abdominal ultrasound. Initial screening was followed by a detailed check-up, and the selected subjects were confirmed to be free of cancer.

Subjects were then asked to complete a self-administered questionnaire that included questions on age, sex, occupation, personal medical history and family history of disease, as well as on lifestyle, namely smoking and drinking habits.

Of the 508 initial subjects, 300 were selected on the basis of CagA seropositivity $\left(\geqslant 10 \mathrm{U} \mathrm{ml}^{-1}\right)$. As CagA is a better biomarker than $\mathrm{Hp}$ in the detection of $H$. pylori infection because of the dominance of the CagA-positive strain in the H. pylori-infecting Japanese patients and because of its longer presence in serum. ${ }^{12}$

Genomic DNA was extracted from peripheral blood using a DNA Extractor WB kit (Wako, Osaka, Japan) according to the manufacturer's protocol. Genotyping was performed using the MassARRAY system (Sequenom, San Diego, CA, USA) for the following 15 GST single-nucleotide polymorphisms (SNPs): GST-mu2 (GST-M2; rs655315 and rs428434), GST-mu3 (GST-M3; rs1332018, rs1537324, rs1571858, rs7483 (Val224Ile) and rs1537236), GST-pi1
(GST-P1; rs1871042, rs762803, rs947894 (Ile105Val) and rs4891) and GSTtheta2 (GST-T2; rs140186, rs2267047, rs1622002 (Met139Ile) and rs2719).

Immunoglobin $\mathrm{G}$ antibody titer levels of $\mathrm{Hp}$ and $\mathrm{CagA}$ were measured using direct ELISA kits, namely the E Plate 'Eiken' Hp antibody (Eiken Kagaku, Tokyo, Japan) and CagA kits (IgG EIA; Sceti, Rome, Italy), respectively. IgG titer levels were then determined by measuring the optical density, which was compared with a standard curve. Serum levels of pepsinogen (PG) I and PGII were measured by two-step enzyme immunoassay using commercial kits (E Plate 'Eiken' PG I and PG II, Eiken Kagaku).

\section{Statistical analysis}

Subjects were classified into three equal groups on the basis of the percentile (33 and $67 \%$ ) value of the IgG titer level and described as low, middle and high groups. The threshold values of the titer groups were 29.9 and $103.5 \mathrm{U} \mathrm{ml}^{-1}$ for CagA and 29.9 and $68.6 \mathrm{U} \mathrm{ml}^{-1}$ for $\mathrm{Hp}$, respectively. The differences in the characteristics of subjects among all three groups were determined using oneway analysis of variance, $\chi^{2}$-test or Kruskal-Wallis test. Each polymorphism was assessed in all subjects to ensure a fit with the Hardy-Weinberg equilibrium. The age-sex adjusted odds ratios (ORs) and $95 \%$ confidence intervals (CIs) of the major allele in the middle and low titer groups were calculated using a polytomous logistic regression model, with the high titer group considered as control. The difference in the PGI mean levels between genotypes was determined using Student's $t$-test. All statistical analysis was performed using SAS, version 9.1 (SAS Institute, Cary, NC, USA). Results were considered statistically significant at $P<0.05$.

\section{RESULTS}

A detailed description of the study subjects is shown in Table 1. No significant differences in age or body mass index were observed among

Table 1 Characteristics of subjects

\begin{tabular}{|c|c|c|c|c|c|c|c|c|c|c|}
\hline & \multicolumn{10}{|c|}{ CagA seropositive } \\
\hline & \multirow[b]{2}{*}{$\begin{array}{l}\text { CagA seronegative } \\
\qquad \mathrm{n}=208\end{array}$} & \multirow[b]{2}{*}{$\begin{array}{c}\text { Total } \\
(\mathrm{n}=300)\end{array}$} & \multicolumn{3}{|c|}{ CagA } & \multirow[b]{2}{*}{$\mathrm{P}$-value } & \multicolumn{3}{|c|}{$H p$} & \multirow[b]{2}{*}{ P-value } \\
\hline & & & $\begin{array}{l}\text { Low titer } \\
(\mathrm{n}=100)\end{array}$ & $\begin{array}{l}\text { Middle titer } \\
\quad(\mathrm{n}=100)\end{array}$ & $\begin{array}{l}\text { High titer } \\
(\mathrm{n}=100)\end{array}$ & & $\begin{array}{l}\text { Low titer } \\
(\mathrm{n}=100)\end{array}$ & $\begin{array}{l}\text { Middle titer } \\
\quad(\mathrm{n}=100)\end{array}$ & $\begin{array}{l}\text { High titer } \\
(\mathrm{n}=100)\end{array}$ & \\
\hline \multicolumn{11}{|l|}{ Age } \\
\hline Mean (s.d.) & $56.6(9.7)$ & $59.5(8.7)$ & $59.8(8.4)$ & $60.2(8.5)$ & $58.3(9.1)$ & $0.270^{a}$ & $58.4(9.7)$ & $60.0(8.8)$ & $59.9(7.3)$ & $0.330^{a}$ \\
\hline \multicolumn{11}{|l|}{ Sex } \\
\hline Man/woman & $141 / 67$ & 203/97 & $73 / 27$ & $73 / 27$ & $57 / 43$ & $0.020^{b}$ & $65 / 35$ & $71 / 29$ & $67 / 33$ & $0.653^{b}$ \\
\hline \multicolumn{11}{|l|}{$B M I$} \\
\hline Mean (s.d.) & 23.7 (2.9) & $23.7(2.7)$ & $23.9(2.7)$ & $23.1(2.6)$ & $23.9(2.8)$ & $0.059^{a}$ & $23.6(2.9)$ & $23.6(2.7)$ & $23.8(2.6)$ & $0.782^{a}$ \\
\hline \multicolumn{11}{|l|}{ Smoking status } \\
\hline Current & 62 & 60 & 24 & 25 & 11 & & 23 & 25 & 12 & \\
\hline Ex- & 44 & 77 & 27 & 28 & 22 & & 28 & 24 & 25 & \\
\hline Never & 102 & 162 & 49 & 46 & 67 & & 48 & 51 & 63 & \\
\hline Unknown & 0 & 1 & 0 & 1 & 0 & $0.020^{b}$ & 1 & 0 & 0 & $0.109^{b}$ \\
\hline \multicolumn{11}{|l|}{ CagA titer } \\
\hline Median (IQR) & $4.1(4.3)$ & $58.4(122.5)$ & $15.2(9.1)$ & $58.1(28.2)$ & $181.1(74.8)$ & $<0.0001^{c}$ & $18.3(25.4)$ & $63.1(104.8)$ & $142.9(133.5)$ & $<0.0001^{\mathrm{c}}$ \\
\hline \multicolumn{11}{|l|}{ Hp titer } \\
\hline Median (IQR) & $0.9(4.4)$ & $48.6(58.4)$ & $15.7(36.5)$ & $45.7(44.4)$ & $76.2(68.3)$ & $<0.0001^{\mathrm{c}}$ & $12.2(18.7)$ & $48.5(14.6)$ & $104.0(71.0)$ & $<0.0001^{c}$ \\
\hline \multicolumn{11}{|l|}{ Pepsinogen1 } \\
\hline Mean (s.d.) & $56.4(23.4)$ & $63.7(31.7)$ & $53.7(26.1)$ & $62.8(28.7)$ & $74.6(36.0)$ & $<0.0001^{a}$ & $52.8(28.8)$ & $64.4(27.1)$ & $74.1(35.0)$ & $<0.0001^{a}$ \\
\hline
\end{tabular}

Abbreviations: $\mathrm{Hp}$, IgG antibody against the surface antigen of Helicobacter pylori; IQR, intraquartile range. 
Table 2 Frequencies for the minor alleles and results from the HardyWeinberg test

\begin{tabular}{|c|c|c|c|}
\hline SNP no. & $\begin{array}{l}\text { Amino-acid } \\
\text { change }\end{array}$ & $\begin{array}{c}\text { Allele } \\
\text { frequency }\end{array}$ & $\begin{array}{c}\text { Hardy-Weinberg } \\
\text { P-value }\end{array}$ \\
\hline \multicolumn{4}{|l|}{ GST-P1 } \\
\hline rs947894 & Ile105Val & 0.18 & 0.57 \\
\hline rs4891 & Ser185Ser & 0.17 & 0.45 \\
\hline rs1871042 & Intron & 0.17 & 0.61 \\
\hline rs762803 & Intron & 0.17 & 0.98 \\
\hline \multicolumn{4}{|l|}{ GST-T2 } \\
\hline rs1622002 & Met139lle & 0.19 & 0.66 \\
\hline rs2719 & Untranslated & 0.28 & 0.94 \\
\hline rs2267047 & Intron & 0.33 & 0.16 \\
\hline rs140186 & Untranslated & 0.47 & 0.95 \\
\hline \multicolumn{4}{|l|}{ GST-M2 } \\
\hline rs655315 & Intron & 0.26 & 0.62 \\
\hline rs428434 & Intron & 0.23 & 0.00 \\
\hline \multicolumn{4}{|l|}{ GST-M3 } \\
\hline rs1537234 & Intron & 0.19 & 0.78 \\
\hline rs7483 & Val224Ile & 0.24 & 0.70 \\
\hline rs1571858 & Intron & 0.25 & 0.94 \\
\hline rs1332018 & Untranslated & 0.19 & 0.48 \\
\hline rs1537236 & Untranslated & 0.19 & 0.69 \\
\hline
\end{tabular}

Abbreviations: GST, glutathione S-transferases; SNP, single-nucleotide polymorphism. a $\chi^{2}$-test.

CagA seropositive cases. A significant difference was observed for sex and smoking status, with the highest number of women and neversmokers found in the high CagA titer group.

Table 2 shows the minor allele frequencies of each polymorphism, as well as the results from the Hardy-Weinberg equilibrium test. Except for SNP rs428434, the $P$-value calculated using the $\chi^{2}$-test exceeded 0.05 , indicating that other SNPs were compatible with the Hardy-Weinberg equilibrium.

Tables 3 and 4 show allele frequencies of each SNP based on the IgG titer levels, as well as the ORs and 95\% CIs for CagA and Hp, respectively. Although no significant associations were observed between CagA or Hp titers and GST-P1, GST-T2 and GST-M2 SNPs, significant associations were found between GST-M3 SNPs and both CagA and $\mathrm{Hp}$ titer levels, in particular for the rs7483 (Val224Ile) SNP based on the $\chi^{2}$-test. In addition, the subjects with AA genotype showed a significantly low risk for being in the low titer group (OR: $0.48,95 \%$ CI: $0.27-0.86$ and OR: $0.46,95 \%$ CI: $0.26-0.83$ for CagA and Hp, respectively). Further, ORs adjusted for smoking status were 0.47 (95\% CI: $0.26-0.86)$ for both CagA and Hp. Haplotype analysis showed no differences in OR between the AA genotype with both rs7483 and rs1332018 SNPs and with the rs7483 SNP alone (OR: 0.50 (95\% CI: 0.28-0.90) and OR: 0.49 (95\% CI: $0.28-0.88$ ) for the low titer group of CagA and Hp, respectively).

Evaluation of GST-M3 alleles containing polymorphisms rs7483 and rs1571858 revealed significantly higher PG1 levels than did genotypes harboring a $\mathrm{G}$ allele (mean (s.d.) for rs7483: 66.9 (32.0) and 59.1 (30.7) $\mu \mathrm{g} \mathrm{ml}^{-1}(P=0.036)$, rs1571858: 67.4 (32.1) and 58.8 (30.5) $\mu \mathrm{g} \mathrm{ml}^{-1}(P=0.020)$ for AA and AG+GG alleles, respectively), despite no significant difference in the PG1/PG2 ratios between genotypes (data not shown). High $\left(\geqslant 70 \mu \mathrm{g} \mathrm{ml}^{-1}\right)$ and low $\left(<70 \mu \mathrm{g} \mathrm{ml}^{-1}\right)$ PGI levels indicate normal and atrophied mucosa $\left(<30 \mu \mathrm{g} \mathrm{ml}^{-1}\right.$ severe atrophy), respectively. The association between GST-M3 genotypes and serum PGI levels is shown in Table 5. Results show an association between the rs1571858 SNP and PGI levels with a borderline significance.

Table 6 shows the linkages among GSTM3 SNPs. A close association was found between genotypes and five SNPs $(P<0.0001)$. Of the 176 major samples with AA alleles in SNP rs7483, 176 (TT), 170 (AA), 174 (AA) and 176 (AA) samples contained SNP rs1537234, rs1571858, rs1332018 and rs1537236, respectively. Of the 106 samples with the AG genotype in SNP rs7483, 17 (TT) and 86 (GT) (three missing samples) contained SNP rs1537234; 106 (AG) rs1571858; 19 (AA) rs1332018; and 17 (AA) and 87 (AC) (one missing sample) rs1537236. Of the 18 minor samples with GG alleles in SNP rs7483, 1 (TT), 7 (GT) and 10 (GG) contained SNP rs1537234; 18 (GG) rs1571858; 1 (AA), 8 (AC) and 9 (CC) rs1332018; and 1 (AA), 7 (AG) and 10 (GG) rs1537236.

\section{DISCUSSION}

This study considers statistical multiplicity based on the repetition of statistical tests. Results show a close association among five SNPs in GST-M3, with similar results for CagA and Hp, which suggests, without coincidental significance, that GST-M3 SNPs are associated with IgG titer levels in serum against $H$. pylori.

The SNP rs7483 in GST-M3 is responsible for a conservative amino-acid substitution, which alters GST-M3 enzyme activity. At codon 224, the A and G alleles code for isoleucine (Ile) and valine (Val), respectively. ${ }^{16} \mathrm{~A}$ study shows that the presence of the Ile residue in GST-M3 results in increased enzymatic activity. ${ }^{17}$ Furthermore, a report shows that the rs 1332018 SNP significantly affects promoter activity. ${ }^{18}$ In contrast, GST-M3 expression is shown to be lower in individuals with the $\mathrm{C}$ allele than the A allele. ${ }^{18}$ Although these findings suggest that the AA genotype with both the rs7483 and rs1332018 SNPs causes higher enzyme activity, haplotype analysis in this study did not reveal more prominent associations. Regarding this point, we consider that the GST-M3 SNPs studied in this study were closely linked and that the haplotype construction of GST-M3 was not informative.

Two possible biological mechanisms are suggested for the low IgG titer levels against $H$. pylori: (1) prolonged $H$. pylori infection leading to the progression of mucosal atrophy, and (2) low initial immunoresponse to $H$. pylori. These mechanisms were investigated by measuring the levels of PGI, a practical biomarker in the determination of the status of the gastric mucosa. ${ }^{19}$ An earlier report showed that low PGI values indicate progression of mucosal atrophy. ${ }^{20}$ In this study, the level of PGI was significantly higher in the AA genotype than in the AG+GG genotype, suggesting that genotypes causing higher GST-M3 activity are involved in protection from mucosal atrophy progression. In this study, no significant differences in PG1/PG2 ratios were observed among the GST-M3 genotypes. We reported earlier the close association between IgG titer levels and serum PG2 but not PG1 levels. ${ }^{8,13}$ A histological study also showed that inflammation in the gastric mucosa elevated serum PG2 but not PG1 levels, leading to a decrease in PG1/PG2 ratios; nevertheless, mucosal atrophy was not histologically observed. ${ }^{21}$ Given that the accuracy of the PG1/PG2 ratio as a biomarker for gastric mucosal atrophy depends on the IgG titer levels and mucosal inflammation grades, the PG1/PG2 ratio was not considered a suitable marker in this study.

This study also observed an association between female neversmokers and high CagA titer. We reported earlier a relationship between 
CagA titer

\begin{tabular}{|c|c|c|c|c|c|c|c|c|c|c|c|}
\hline \multirow[b]{3}{*}{ Gene } & \multirow[b]{3}{*}{ SNP ID } & \multirow[b]{3}{*}{ Genotype } & \multirow[b]{3}{*}{ Total no. } & & & & & & & & \multirow[b]{3}{*}{ P-value b } \\
\hline & & & & \multirow{2}{*}{$\begin{array}{l}\text { High } \\
\text { No. }\end{array}$} & \multicolumn{3}{|c|}{ Middle } & \multicolumn{3}{|c|}{ Low } & \\
\hline & & & & & No. & $O R^{\mathrm{a}}$ & $95 \% \mathrm{Cl}^{\mathrm{a}}$ & No. & $O R^{a}$ & $95 \% \mathrm{Cl}^{\mathrm{a}}$ & \\
\hline & & $\mathrm{AA}$ & 200 & 61 & 68 & 1.35 & $0.75,2.43$ & 71 & 1.67 & $0.91,3.05$ & 0.224 \\
\hline & rs4891 & $\mathrm{TC}+\mathrm{CC}$ & 96 & 39 & 31 & 1 & Reference & 26 & 1 & Reference & \\
\hline & & TT & 204 & 61 & 69 & 1.40 & $0.77,2.53$ & 74 & 1.78 & $0.97,3.28$ & 0.139 \\
\hline & rs762803 & $C A+A A$ & 94 & 37 & 29 & 1 & Reference & 28 & 1 & Reference & \\
\hline & & $\mathrm{CC}$ & 203 & 62 & 70 & 1.43 & $0.78,2.61$ & 71 & 1.50 & $0.82,2.75$ & 0.321 \\
\hline \multirow[t]{4}{*}{ GST-T2 } & rs1622002 & $A G+A A$ & 102 & 31 & 32 & 1 & Reference & 39 & 1 & Reference & \\
\hline & & GG & 198 & 69 & 68 & 0.92 & $0.50,1.69$ & 61 & 0.67 & $0.37,1.22$ & 0.429 \\
\hline & rs2719 & $\mathrm{TG}+\mathrm{TT}$ & 143 & 47 & 51 & 1 & Reference & 45 & 1 & Reference & \\
\hline & & GG & 153 & 53 & 48 & 0.91 & $0.52,1.60$ & 52 & 1.11 & $0.63,1.97$ & 0.734 \\
\hline \multirow[t]{4}{*}{ GST-M2 } & rs655315 & $A G+A A$ & 133 & 42 & 47 & 1 & Reference & 44 & 1 & Reference & \\
\hline & & GG & 162 & 55 & 52 & 0.86 & $0.48,1.52$ & 55 & 0.96 & $0.54,1.71$ & 0.831 \\
\hline & rs428434 & CG & 135 & 42 & 48 & 1 & Reference & 45 & 1 & Reference & \\
\hline & & GG & 164 & 58 & 51 & 0.78 & $0.44,1.37$ & 55 & 0.89 & $0.51,1.57$ & 0.655 \\
\hline \multirow[t]{7}{*}{ GST-M3 } & rs1537234 & $T G+G G$ & 103 & 27 & 32 & 1 & Reference & 44 & 1 & Reference & \\
\hline & & $\mathrm{TT}$ & 194 & 73 & 66 & 0.77 & $0.41,1.43$ & 55 & 0.46 & $0.25,0.84$ & 0.031 \\
\hline & rs7483 & $\mathrm{GA}+\mathrm{GG}$ & 124 & 32 & 42 & 1 & Reference & 50 & 1 & Reference & \\
\hline & & $\mathrm{AA}$ & 176 & 68 & 58 & 0.68 & $0.38,1.22$ & 50 & 0.48 & $0.27,0.86$ & 0.035 \\
\hline & rs1571858 & $A G+G G$ & 130 & 33 & 44 & 1 & Reference & 53 & 1 & Reference & \\
\hline & & $\mathrm{AA}$ & 170 & 67 & 56 & 0.64 & $0.36,1.15$ & 47 & 0.44 & $0.25,0.79$ & 0.017 \\
\hline & rs1332018 & $\mathrm{CA}+\mathrm{CC}$ & 105 & 27 & 34 & 1 & Reference & 44 & 1 & Reference & \\
\hline
\end{tabular}

Abbreviations: $\mathrm{Cl}$, confidence interval; GST, glutathione S-transferases; OR, odds ratio; SNP, single-nucleotide polymorphism.

aAge-sex adjusted OR was calculated using a polytomous logistic regression model, with the high titer level considered as control.

b. $\chi^{2}$-test.

smoking status and reduced IgG titer levels. ${ }^{8}$ On the basis of this finding, two possible mechanisms for decreased IgG titer levels are suggested: (1) smoking reduces immunological reactions because of the hampering $H$. pylori survival, leading to a decreased number infected and an inhibition of IgG titer increase, and (2) the proinflammatory and toxic effects of smoking enhance mucosal destruction, resulting in rapid mucosal atrophy, and hampered $H$. pylori survival.

The brain is known to show high oxygen metabolism and sensitivity to oxidative stress. Recent studies report that polymorphisms in GSTM3, a key enzyme in the protection of tissue from oxidative species, are associated with a risk of Alzheimer's disease. ${ }^{16,22}$ Pathogenic changes of the gastric mucosa, which was shown to be sensitive to oxidative radicals, are also caused by oxidative stress mediated by H. pylori infection. ${ }^{23}$ These findings suggest the crucial role of GST-M3 in the pathogenesis of gastric mucosa.

The mu class of GST isoforms is most abundant in the liver, muscle and brain, ${ }^{24-26}$ whereas GST- $\alpha$, GST-T1and GST-P1 are commonly expressed in the gastrointestinal tract. ${ }^{27}$ Although a number of earlier studies investigated the association between the risk of gastric cancer and deletion mutations in GST-T1 and GST-M1, the results were inconclusive. ${ }^{28}$ You et al. ${ }^{29}$ reported that there was no significant association of the precancerous gastric lesions with null genotype of GST-P1, M1 or T1 in a large-scale Chinese population. A recent metaanalysis study, however, reported a minor increase in the risk of gastric cancer in GST-T1-null genotypes. ${ }^{5}$ The association between GST-M3 polymorphisms and risk of cancer was studied in the prostate, ${ }^{30}$ esophagus, ${ }^{31}$ larynx, ${ }^{32}$ colorectal, ${ }^{33}$ bladder, ${ }^{34}$ breast $^{35}$ and basal cell carcinomas. ${ }^{36}$ A study on a Polish population, however, reported insufficient evidence of an association between GST-M3 polymorphisms and gastric cancer. ${ }^{37}$ Our recent study also indicates no significant association between GST-M3 polymorphisms and gastric cancer. ${ }^{15}$ Although necessary to induce mucosal atrophy, H. pylori infection is not a sufficient causal factor of gastric cancer, which is a multifactorial disease. ${ }^{2}$ Furthermore, additional combinations of polymorphic GST enzymes may possibly affect the risk of cancer. Clarification of the association between GST-M3 polymorphisms and gastric cancer risk is therefore required through analysis of genegene and gene-environment interactions.

Results from our earlier study, ${ }^{8}$ as well as pathological findings, ${ }^{38,39}$ show low levels of IgG titer and PGI in currently smoking individuals, suggesting that smoking promotes mucosal atrophy in subjects infected by $H$. pylori. This finding is consistent with results in this 


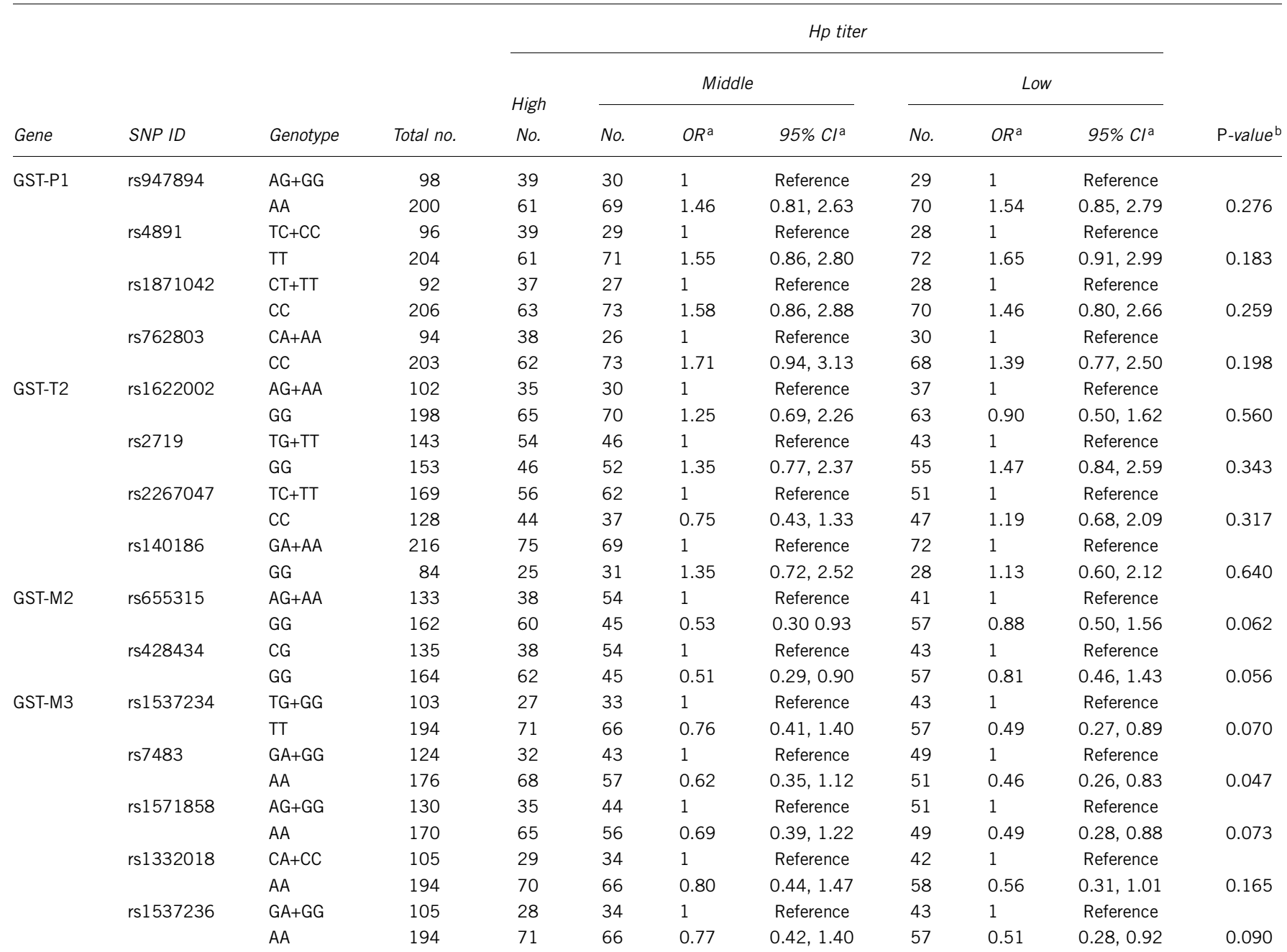

Abbreviations: $\mathrm{Cl}$, confidence interval; GST, glutathione S-transferases; Hp, IgG antibody against the surface antigen of Helicobacter pylori; OR, odds ratio; SNP, single-nucleotide polymorphism. ${ }^{a}$ Age-sex adjusted OR was calculated using a polytomous logistic regression model, with the high titer level considered as control.

b $\chi^{2}$-test.

Table 5 Association of GST-M3 genotypes with serum pepsinogen 1 levels

\begin{tabular}{|c|c|c|c|c|c|c|c|c|c|c|c|}
\hline \multirow[b]{3}{*}{ Gene } & \multirow[b]{3}{*}{$S N P I D$} & \multirow[b]{3}{*}{ Genotype } & \multirow[b]{3}{*}{ Total no. } & \multicolumn{7}{|c|}{ Pepsinogen $1\left(\mu g \mathrm{ml}^{-1}\right)$} & \multirow[b]{3}{*}{ P-value } \\
\hline & & & & \multirow{2}{*}{$\frac{\geqslant 70}{\text { No. }}$} & \multicolumn{3}{|c|}{$70-30$} & \multicolumn{3}{|c|}{$<30$} & \\
\hline & & & & & No. & $O R^{\mathrm{b}}$ & $95 \% \mathrm{Cl}^{\mathrm{b}}$ & No. & $O R^{b}$ & $95 \% \mathrm{Cl}^{\mathrm{b}}$ & \\
\hline \multirow[t]{10}{*}{ GST-M3 } & rs1537234 & $\mathrm{TG}+\mathrm{GG}$ & 100 & 28 & 60 & 1 & Reference & 12 & 1 & Reference & \\
\hline & & $\mathrm{TT}$ & 190 & 70 & 99 & 0.64 & $0.37,1.10$ & 21 & 0.76 & $0.33,1.77$ & 0.315 \\
\hline & rs7483 & $\mathrm{GA}+\mathrm{GG}$ & 118 & 33 & 67 & 1 & Reference & 18 & 1 & Reference & \\
\hline & & AA & 175 & 66 & 92 & 0.66 & $0.39,1.12$ & 17 & 0.51 & $0.23,1.13$ & 0.134 \\
\hline & rs1571858 & $A G+G G$ & 124 & 34 & 70 & 1 & Reference & 20 & 1 & Reference & \\
\hline & & $\mathrm{AA}$ & 169 & 65 & 89 & 0.64 & $0.38,1.09$ & 15 & 0.42 & $0.19,0.92$ & 0.052 \\
\hline & rs1332018 & $\mathrm{CA}+\mathrm{CC}$ & 102 & 28 & 60 & 1 & Reference & 14 & 1 & Reference & \\
\hline & & $\mathrm{AA}$ & 190 & 71 & 98 & 0.63 & $0.36,1.08$ & 21 & 0.62 & $0.28,1.40$ & 0.227 \\
\hline & rs1537236 & $\mathrm{GA}+\mathrm{GG}$ & 102 & 29 & 59 & 1 & Reference & 14 & 1 & Reference & \\
\hline & & $\mathrm{AA}$ & 190 & 70 & 99 & 0.67 & $0.39,1.16$ & 21 & 0.66 & $0.29,1.50$ & 0.336 \\
\hline
\end{tabular}

Abbreviations: $\mathrm{Cl}$, confidence interval; GST, glutathione $S$-transferases; OR, odds ratio; SNP, single-nucleotide polymorphism.

a. $\chi^{2}$-test.

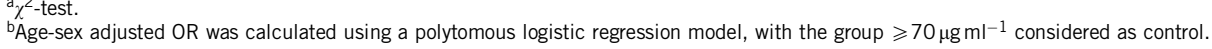


Table 6 Linkage among single-nucleotide polymorphisms of GST-M3

\begin{tabular}{|c|c|c|c|c|c|}
\hline \multirow[b]{2}{*}{ SNP no. } & \multirow[b]{2}{*}{ Genotype } & \multicolumn{3}{|c|}{$r s 7483$} & \multirow[b]{2}{*}{ P-value } \\
\hline & & $A A$ & $A G$ & $G G$ & \\
\hline \multirow[t]{3}{*}{ rs1537234 } & $\mathrm{TT}$ & 176 & 17 & 1 & \\
\hline & GT & 0 & 86 & 7 & \\
\hline & GG & 0 & 0 & 10 & $<0.0001$ \\
\hline \multirow[t]{3}{*}{ rs1571858 } & $A A$ & 170 & 0 & 0 & \\
\hline & $A G$ & 6 & 106 & 0 & \\
\hline & GG & 0 & 0 & 18 & $<0.0001$ \\
\hline \multirow[t]{3}{*}{ rs1332018 } & $A A$ & 174 & 19 & 1 & \\
\hline & $A C$ & 1 & 87 & 8 & \\
\hline & $\mathrm{CC}$ & 0 & 0 & 9 & $<0.0001$ \\
\hline \multirow[t]{3}{*}{ rs1537236 } & AA & 176 & 17 & 1 & \\
\hline & $A G$ & 0 & 88 & 7 & \\
\hline & GG & 0 & 0 & 10 & $<0.0001$ \\
\hline
\end{tabular}

study (unpublished data). GST-M3 is a phase II enzyme that has a key role in the detoxification of chemical agents from smoking, whereas there was no interaction effect of GST-M3 polymorphisms and IgG titer levels in this study (unpublished data). These results suggest that cigarette smoking could promote the progression of mucosal atrophy and affect gastric mucosa infected by $H$. pylori. In addition to chemical toxicity, other causal factors may be involved in mucosal atrophy because of smoking, such as impairment of mucosal microcirculation, modulation of acid secretion, and increase in bile-to-stomach reflex. ${ }^{40}$

In summary, this study is the first to suggest an association between GST-M3 polymorphisms and IgG titer levels in serum against $H$. pylori. Further, the high activity of GST-M3 may be involved in protection against mucosal atrophy caused by $H$. pylori. Given these findings, the presence of GST-M3 polymorphisms should be considered in assessments using titers against $H$. pylori.

\section{ACKNOWLEDGEMENTS}

The authors thank Drs Syusuke Natsukawa, Saku General Hospital, Nagano, Japan; Kozo Shaura, Hokushin General Hospital, Nagano, Japan; Yoichi Koizumi, Shinonoi General Hospital, Nagano, Japan; and Yoshio Kasuga, Nagano Matsushiro General Hospital, Nagano, Japan for recruiting study subjects and collecting samples. This study was supported by the Third Term Comprehensive 10-year Strategy for Cancer Control (H21-Sanjigan-lppan-003) from the Ministry of Health, Labour and Welfare of Japan.

1 Chey, W. D. \& Wong, B. C. American College of Gastroenterology guideline on the management of Helicobacter pylori infection. Am. J. Gastroenterol. 102, 1808-1825 (2007).

2 Malfertheiner, P., Megraud, F., O'Morain, C., Bazzoli, F., El-Omar, E., Graham, D. et al. Current concepts in the management of Helicobacter pylori infection: the Maastricht III Consensus Report. Gut. 56, 772-781 (2007).

3 Correa, P. Does Helicobacter pylori cause gastric cancer via oxidative stress? Biol. Chem. 387, 361-364 (2006)

4 Ketterer, B. Protective role of glutathione and glutathione transferases in mutagenesis and carcinogenesis. Mutat. Res. 202, 343-361 (1988).

5 Boccia, S., La Torre, G., Gianfagna, F., Mannocci, A. \& Ricciardi, G. Glutathione $S$-transferase T1 status and gastric cancer risk: a meta-analysis of the literature. Mutagenesis. 21, 115-123 (2006).

6 Hayes, J. D., Flanagan, J. U. \& Jowsey, I. R. Glutathione transferases. Annu. Rev. Pharmacol. Toxicol. 45, 51-88 (2005).

7 Blecker, U., Lanciers, S., Hauser, B., Mehta, D. I. \& Vandenplas, Y. Serology as a valid screening test for Helicobacter pylori infection in asymptomatic subjects. Arch. Pathol. Lab. Med. 119, 30-32 (1995).
8 Tatemichi, M., Kabuto, M. \& Tsugane, S. Effect of smoking on serum pepsinogen I level depends on serological status of Helicobacter pylori. Jpn. J. Cancer. Res. 92, 243-248 (2001).

9 Koizumi, W., Tanabe, S., Imaizumi, H., Hibi, K., Kida, M., Ohida, M. et al. Effect of anti-Helicobacter pylori IgG antibody titer following eradication of Helicobacter pylori infection. Hepatogastroenterology 50, 293-296 (2003).

10 Suzuki, G., Cullings, H., Fujiwara, S., Hattori, N., Matsuura, S., Hakoda, M. et al. Low-positive antibody titer against Helicobacter pylori cytotoxin-associated gene A (CagA) may predict future gastric cancer better than simple seropositivity against $H$. pylori CagA or against H. pylori. Cancer Epidemiol. Biomarkers Prev. 16, 1224-1228 (2007).

11 Tatemichi, M., Hamada, G. S., Nishimoto, I. N., Kowalski, L. P., Iriya, K., Rodrigues, J. J. et al. Ethnic difference in serology of Helicobacter pylori CagA between Japanese and non-Japanese Brazilians for non-cardia gastric cancer. Cancer Sci. 94, 64-69 (2003).

12 Maeda, S., Yoshida, H., Ogura, K., Yamaji, Y., Ikenoue, T., Mitsushima, T. et al. Assessment of gastric carcinoma risk associated with Helicobacter pylori may vary depending on the antigen used: CagA specific enzyme-linked immunoadsorbent assay (ELISA) versus commercially available H. pylori ELISAs. Cancer 88, 1530-1535 (2000).

13 Tatemichi, M., Sasazuki, S., Inoue, M. \& Tsugane, S. Different etiological role of Helicobacter pylori $(\mathrm{Hp})$ infection in carcinogenesis between differentiated and undifferentiated gastric cancers: a nested case-control study using IgG titer against $\mathrm{Hp}$ surface antigen. Acta. Oncol. 47, 360-365 (2008).

14 Hamajima, N., Naito, M., Kondo, T. \& Goto, Y. Genetic factors involved in the development of Helicobacter pylori-related gastric cancer. Cancer Sci. 97, 11291138 (2006).

15 Ikeda, S., Sasazuki, S., Natsukawa, S., Shaura, K., Koizumi, Y., Kasuga, Y. et al. Screening of 214 single nucleotide polymorphisms in 44 candidate cancer susceptibility genes: a case-control study on gastric and colorectal cancers in the Japanese population. Am. J. Gastroenterol. 103, 1476-1487 (2008).

16 Maes, O. C., Schipper, H. M., Chong, G., Chertkow, H. M. \& Wang, E. A GSTM3 polymorphism associated with an etiopathogenetic mechanism in Alzheimer disease. Neurobiol. Aging (2009) (in press).

17 Tetlow, N., Robinson, A., Mantle, T. \& Board, P. Polymorphism of human mu class glutathione transferases. Pharmacogenetics 14, 359-368 (2004).

18 Liu, X., Campbell, M. R., Pittman, G. S., Faulkner, E. C., Watson, M. A. \& Bell, D. A. Expression-based discovery of variation in the human glutathione S-transferase M3 promoter and functional analysis in a glioma cell line using allele-specific chromatin immunoprecipitation. Cancer Res. 65, 99-104 (2005).

19 Miki, K. \& Urita, Y. Using serum pepsinogens wisely in a clinical practice. J. Dig. Dis. 8, 8-14 (2007).

20 Huang, S. C., Miki, K., Hirano, K., Hayashi, Y., Furihata, C., Shimizu, A. et al. Enzyme-linked immunosorbent assay of serum pepsinogen I. Clin. Chim. Acta. 162, 85-96 (1987)

21 Onoda, N., Katsuragi, K., Maeda, K., Sawada, T., Wakasa, K. \& Hirakawa, K. Helicobacter pylori infection, but not mucosal atrophy, significantly affects serum pepsinogen level after gastric cancer surgery. Hepatogastroenterology 53, 619-623 (2006).

22 Hong, G. S., Heun, R., Jessen, F., Popp, J., Hentschel, F., Kelemen, P. et al. Gene variations in GSTM3 are a risk factor for Alzheimer's disease. Neurobiol. Aging 30, 691-696 (2009).

23 Naito, Y. \& Yoshikawa, T. Molecular and cellular mechanisms involved in Helicobacter pylori-induced inflammation and oxidative stress. Free Radic. Biol. Med. 33, 323-336 (2002).

24 Laisney, V., Nguyen Van, C., Gross, M. S. \& Frezal, J. Human genes for glutathione S-transferases. Hum. Genet. 68, 221-227 (1984).

25 Rowe, J. D., Nieves, E. \& Listowsky, I. Subunit diversity and tissue distribution of human glutathione $S$-transferases: interpretations based on electrospray ionization-MS and peptide sequence-specific antisera. Biochem. J. 325(Pt 2), 481-486 (1997).

26 Suzuki, T., Coggan, M., Shaw, D. C. \& Board, P. G. Electrophoretic and immunological analysis of human glutathione S-transferase isozymes. Ann. Hum. Genet. 51(Part 2), 95-106 (1987).

27 de Bruin, W. C., Wagenmans, M. J. \& Peters, W. H. Expression of glutathione S-transferase alpha, P1-1 and T1-1 in the human gastrointestinal tract. Jpn. J. Cancer Res. 91, 310-316 (2000).

28 La Torre, G., Boccia, S. \& Ricciardi, G. Glutathione S-transferase M1 status and gastric cancer risk: a meta-analysis. Cancer Lett. 217, 53-60 (2005).

29 You, W. C., Hong, J. Y., Zhang, L., Pan, K. F., Pee, D., Li, J. Y. et al. Genetic polymorphisms of CYP2E1, GSTT1, GSTP1, GSTM1, ALDH2, and ODC and the risk of advanced precancerous gastric lesions in a Chinese population. Cancer Epidemiol. Biomarkers Prev. 14, 451-458 (2005).

30 Kesarwani, P., Singh, R. \& Mittal, R. D. Association of GSTM3 intron 6 variant with cigarette smoking, tobacco chewing and alcohol as modifier factors for prostate cancer risk. Arch. Toxicol. 83, 351-356 (2009).

31 Jain, M., Kumar, S., Lal, P., Tiwari, A., Ghoshal, U. C. \& Mittal, B. Role of GSTM3 polymorphism in the risk of developing esophageal cancer. Cancer Epidemiol. Biomarkers Prev. 16, 178-181 (2007).

32 Jourenkova-Mironova, N., Mitrunen, K., Bouchardy, C., Dayer, P., Benhamou, S. \& Hirvonen, A. High-activity microsomal epoxide hydrolase genotypes and the risk of oral, pharynx, and larynx cancers. Cancer Res. 60, 534-536 (2000).

33 Holley, S. L., Rajagopal, R., Hoban, P. R., Deakin, M., Fawole, A. S., Elder, J. B. et al. Polymorphisms in the glutathione $S$-transferase mu cluster are associated with tumour 
progression and patient outcome in colorectal cancer. Int. J. Oncol. 28, 231-236 (2006).

34 Schnakenberg, E., Breuer, R., Werdin, R., Dreikorn, K. \& Schloot, W. Susceptibility genes: GSTM1 and GSTM3 as genetic risk factors in bladder cancer. Cytogenet. Cell. Genet. 91, 234-238 (2000).

35 Mitrunen, K., Jourenkova, N., Kataja, V., Eskelinen, M., Kosma, V. M., Benhamou, S. et al. Glutathione S-transferase M1, M3, P1, and T1 genetic polymorphisms and susceptibility to breast cancer. Cancer Epidemiol. Biomarkers Prev. 10, 229-236 (2001).

36 Yengi, L., Inskip, A., Gilford, J., Alldersea, J., Bailey, L., Smith, A. et al. Polymorphism at the glutathione $S$-transferase locus GSTM3: interactions with cytochrome P450 and glutathione $S$-transferase genotypes as risk factors for multiple cutaneous basal cell carcinoma. Cancer Res. 56, 1974-1977 (1996).
37 Lan, Q., Chow, W. H., Lissowska, J., Hein, D. W., Buetow, K., Engel, L. S. et al. Glutathione $S$-transferase genotypes and stomach cancer in a population-based case-control study in Warsaw, Poland. Pharmacogenetics 11, 655-661 (2001).

38 Koivisto, T. T., Voutilainen, M. E. \& Farkkila, M. A. Effect of smoking on gastric histology in Helicobacter pylori-positive gastritis. Scand. J. Gastrienterol. 43, $1177-$ 1183 (2008).

39 Nakamura, M., Haruma, K., Kamada, T., Mihara, M., Yoshihara, M., Sumioka, M. et al. Cigarette smoking promotes atrophic gastritis in Helicobacter pylori-positive subjects. Dig. Dis. Sci. 47, 675-681 (2002).

40 Maity, P., Biswas, K., Roy, S., Banerjee, R. K. \& Bandyopadhyay, U. Smoking and the pathogenesis of gastroduodenal ulcer-recent mechanistic update. Mol. Cell. Biochem. 253, 329-338 (2003) 